This item was submitted to Loughborough's Research Repository by the author.

Items in Figshare are protected by copyright, with all rights reserved, unless otherwise indicated.

\title{
Spontaneous formation and morphology of telephone cord blisters in thin
} films: The $\Omega$ formulae

PLEASE CITE THE PUBLISHED VERSION

https://doi.org/10.1016/j.compstruct.2019.111108

\section{PUBLISHER}

(C) Elsevier

\section{VERSION}

AM (Accepted Manuscript)

\section{PUBLISHER STATEMENT}

This paper was accepted for publication in the journal Composite Structures and the definitive published version is available at https://doi.org/10.1016/j.compstruct.2019.111108.

\section{LICENCE}

CC BY-NC-ND 4.0

\section{REPOSITORY RECORD}

Yuan, Bo, Christopher Harvey, Rachel Thomson, Gary Critchlow, David S. Rickerby, and Simon Wang. 2019. "Spontaneous Formation and Morphology of Telephone Cord Blisters in Thin Films: The $\Omega$ Formulae". Loughborough University. https://hdl.handle.net/2134/37943. 


\title{
Spontaneous formation and morphology of telephone cord blisters in thin films: The $\Omega$ formulae
}

\author{
Bo Yuan ${ }^{\mathrm{a}, \dagger}$, Christopher M. Harvey ${ }^{\mathrm{a}, \dagger}$, Rachel C. Thomson ${ }^{\mathrm{b}}$, Gary W. Critchlow ${ }^{\mathrm{b}}$, \\ David Rickerby ${ }^{\mathrm{c}}$ and Simon Wang, ${ }^{\mathrm{a}, \mathrm{d}, *}$ \\ ${ }^{a}$ Department of Aeronautical and Automotive Engineering, Loughborough University, \\ Loughborough, Leicestershire LE11 3TU, UK \\ ${ }^{b}$ Department of Materials, Loughborough University, \\ Loughborough, Leicestershire LE11 3TU, UK \\ 'Surface Engineering Precision Institute, Cranfield University, \\ Cranfield, Bedfordshire MK43 OAL, UK
}

${ }^{d}$ School of Mechanical and Equipment Engineering, Hebei University of Engineering, Handan 056038, China

\begin{abstract}
Telephone cord blisters (TCBs) are frequently observed in film/substrate material systems. They nucleate and propagate forward with wavy boundaries between the film and the substrate like worms. The current study views the problem from a completely new angle: It is discovered that the spontaneous formation and morphology of TCBs in thin films under biaxial compressive residual stresses can be accurately explained and determined by assuming the existence of a pocket of energy concentration (PEC) instead of the existence of a separation of critical size. For the first time, completely-analytical formulae - the ' $\Omega$ formulae' - are derived for the two local morphology parameters of TCBs of any shape, that is, width and height, and for the two global morphology parameters of TCBs of sinusoidal shape, that is, the wavelength and transverse amplitude. Mechanical conditions are also given for the first time for the formation of TCBs. Predictions for the four morphology parameters of the developed theory agree very well with extensive experimental results. In addition, by reversing the calculation, the residual stress and the film/substrate interface fracture toughness are also accurately determined from measurements of the TCB morphology parameters.
\end{abstract}

\footnotetext{
* Corresponding Author

$\dagger$ These authors contributed equally to this work.

Email addresses: S.Wang@lboro.ac.uk (S. Wang), B.Yuan@lboro.ac.uk (B. Yuan),

C.M.Harvey@lboro.ac.uk (C. M. Harvey), R.C.Thomson@lboro.ac.uk (R. C. Thomson),

G.W.Critchlow@lboro.ac.uk (G. W. Critchlow), David.Rickerby@cranfield.ac.uk (D. Rickerby)
} 
Keywords: thin films; telephone cord blister; pockets of energy concentration; residual stress; fracture toughness; buckling

\section{Introduction}

Thin solid films are found in many different applications fulfilling various roles [1] such as confinement of electric charge in integrated electronic circuits, thermal insulation in thermal barrier coatings, and protection against corrosion, friction and wear in surface coatings. Although thin films are not usually expected to have a primary load-carrying capability, they often experience residual stresses due to the fabrication process and working conditions. One typical example is the in-plane compressive stress in thermal barrier coatings caused by the mismatch of thermal expansion coefficient between the coating and alloy substrate. Residual stresses are a major cause of film wrinkles, blisters, cracks and de-bonding, which all involve complex instabilities and morphologies [1-5]. So-called buckling-driven delamination is a typical example of film failure under in-plane compressive residual stress, which has been extensively studied in the last few decades. Among many others, Refs. [6-11] report studies on buckling-driven straight blisters [6,8,10], circular blisters [6,7], elliptical blisters [6], telephone cord blisters (TCBs) [9], and branched blisters [11]. Among these different types of blisters, the TCB is the most interesting and challenging one, and predicting TCB morphology has attracted the attention of many researchers worldwide. A recent and comprehensive review on the topic is given in Ref. [12].

In studies on so-called buckling-driven delamination, it is conventional to assume either a pre-existing interface crack which is larger than the critical buckling characteristic dimension or a pre-existing imperfection $[7,9,13,14]$. In some cases, thin-film blisters spontaneously form under constant biaxial compressive residual stresses at sizes which are much smaller than the critical buckling characteristic dimensions $[15,16]$, and so buckling-driven approach is unable to explain the phenomenon. A new hypothesis has recently been proposed by Wang et al. $[17,18]$ to explain this behavior. According to this hypothesis, the delamination is driven by pockets of energy concentration (PECs) in the form of pockets of tensile stress and shear stress $[15,16]$ on and around the interface between a thin film and a thick substrate. Furthermore, PECs can be caused by a number of different processes, including the commonly-seen edge cracks [2,12], indentation cracks [9], thermal cooling such as in thermal barrier coating material systems, electro-chemical reaction such as in solid thin film electrode material systems [19], and thermal heating such as surface pattern fabrication on thin films 
under a scanning laser beam [20]. The exact origin of PECs is not discussed in the current work; instead, the existence of PECs is taken as given and then the mechanical consequences for TCBs are established. What is important, and what is addressed in this work, is whether the developed theory based on the hypothesis of PECs can predict the major behaviors of TCBs.

It is, however, pertinent to describe the essential differences between the PECs hypothesis approach to solving the TCB problem, and the conventional buckling approach. The PECs hypothesis establishes a pure energy balance approach whereby blister growth is driven by an energy source in addition to the constant residual stress. More specifically, with the PECs hypothesis, a blister experiences two stages of growth: During the first stage, the PEC drives the blister's nucleation, its bending-away from the substrate, and its propagation. The blister energy, including the strain energy and fractured surface energy, is larger than the initial residual strain energy in the un-delaminated film and it increases until it reaches a maximum at the end of the first stage. During the second stage, the blister energy decreases again and the blister stops growing when blister energy is balanced with the initial residual strain energy in the un-delaminated film. Since the biaxial compressive residual stresses remain constant in both stages, the TCB formation process can described as 'spontaneous'.

Based on Refs. [6-11] and many others, there are also two stages of blister growth in the buckling-driven approach: During the first stage, the separation nucleates and grows without bending-away from the substrate resulting in zero energy release rate at the separation edge. When the size of separation reaches the conventional buckling size, the separated film starts to bend away from the substrate, resulting in energy release rate at the separation edge, that is, a blister is formed. At a critical size slightly larger than the conventional buckling size the energy release rate exceeds the interface fracture toughness and the second stage starts: The blister quickly grows to a certain size beyond which the energy release rate is lower than the interface fracture toughness, and then stops. A detailed description of the buckling-driven approach is given in Appendix A.

This work views TCB formation and development from the novel mechanical understanding that the blisters are driven by PECs. For the first time, completely analytical formulae - the ' $\Omega$ formulae' - are derived for the TCB width $2 R$, height $A_{x}$, transverse amplitude $A_{y}$ and wavelength $\lambda$, in addition to the mechanical conditions of their formation. The theory is validated by extensive independent experimental results. 


\section{Analytical mechanical model for telephone cord blisters}

\subsection{Nucleation and early-growth of telephone cord blisters}

Fig. 1 shows a TCB nucleating and beginning to grow from an edge. It is approximately in the shape of a thumbnail: It consists of a straight blister, and a half-circular blister that represents the TCB tip. The relevant geometrical parameters are also shown in Fig. 1.

(a)

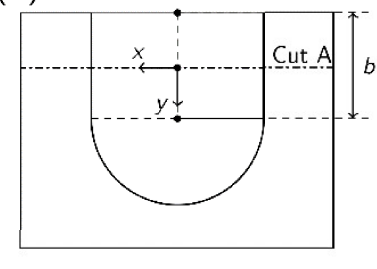

(b)

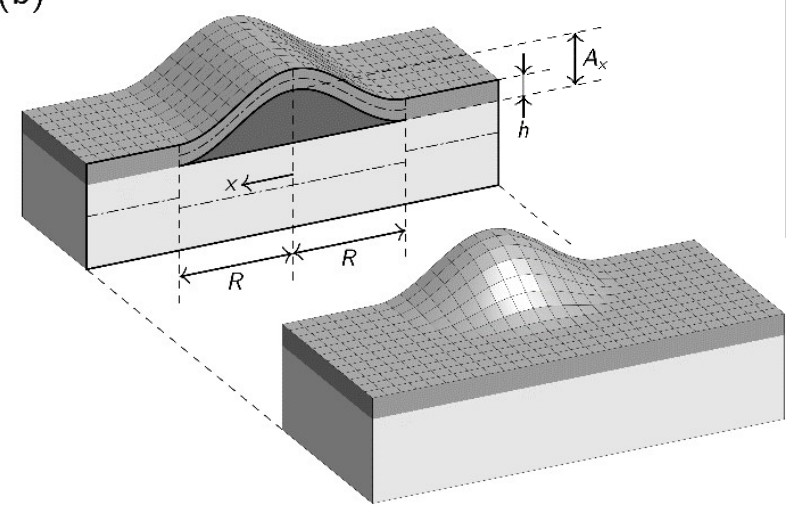

Fig. 1. A telephone cord blister nucleating and beginning to grow from an edge. (a): Top view, (b): $3 \mathrm{D}$ view of cut $\mathrm{A}$ (shown in a).

The blister energy $U_{\mathrm{a}}$ is defined as the difference between the strain energy combined with the interface fracture energy, and the initial residual strain energy in the film. The blister energies during growth for the straight blister and the half-circular blister [17,18] are

$$
\left(U_{\mathrm{a}}\right)_{\mathrm{s}}=2 b R G_{\mathrm{c}}\left\{\frac{3}{2}+\frac{6 \bar{\varepsilon}_{0}}{\pi^{2}}\left(\frac{R}{h}\right)^{2}\left[\frac{3 \bar{\varepsilon}_{0}}{2 \pi^{2} \Omega}\left(\frac{R}{h}\right)^{2}-1\right]\right\}
$$

and

$$
\left(U_{\mathrm{a}}\right)_{\mathrm{c}}=\frac{1}{2} \pi R^{2} G_{\mathrm{c}}\left\{\frac{3}{2}+\frac{6 \bar{\varepsilon}_{0}}{\pi^{2}}\left(\frac{R}{h}\right)^{2}\left[\frac{3 \bar{\varepsilon}_{0}}{2 \pi^{2} \Omega}\left(\frac{R}{h}\right)^{2}-1\right]\right\},
$$

where the subscripts ' $s$ ' and ' $c$ ' denote the straight blister and half-circular blister respectively, $G_{\mathrm{c}}$ is the interface fracture toughness, $\bar{\varepsilon}_{0}=\sigma_{0}\left(1-v^{2}\right) / E$ is the compressive residual strain in the plane-strain condition, $\sigma_{0}$ is the biaxial compressive residual stress in the film, and $E, v$ and $h$ are the Young's modulus, Poisson's ratio and the film thickness respectively. Note that the blister energy during growth of a full-circular blister in a central region (i.e. not from an edge) is $2\left(U_{\mathrm{a}}\right)_{\mathrm{c}}$. The key quantity $\Omega$ represents the ratio between the 
plane-strain energy density and the interface fracture toughness. It will be shown that the $\Omega$ provides the mechanical condition for the formation of a TCB, as follows:

$$
\Omega=\frac{h\left(1-v^{2}\right) \sigma_{0}^{2}}{2 E G_{\mathrm{c}}}>\frac{3}{2} .
$$

The variations of $\left(U_{\mathrm{a}}\right)_{\mathrm{s}}$ and $\left(U_{\mathrm{a}}\right)_{\mathrm{c}}$ with $R$ are presented in Fig. 2 for $\Omega \geq 3 / 2$, which provides the basis for an initial qualitative discussion. Several important observations are noted:

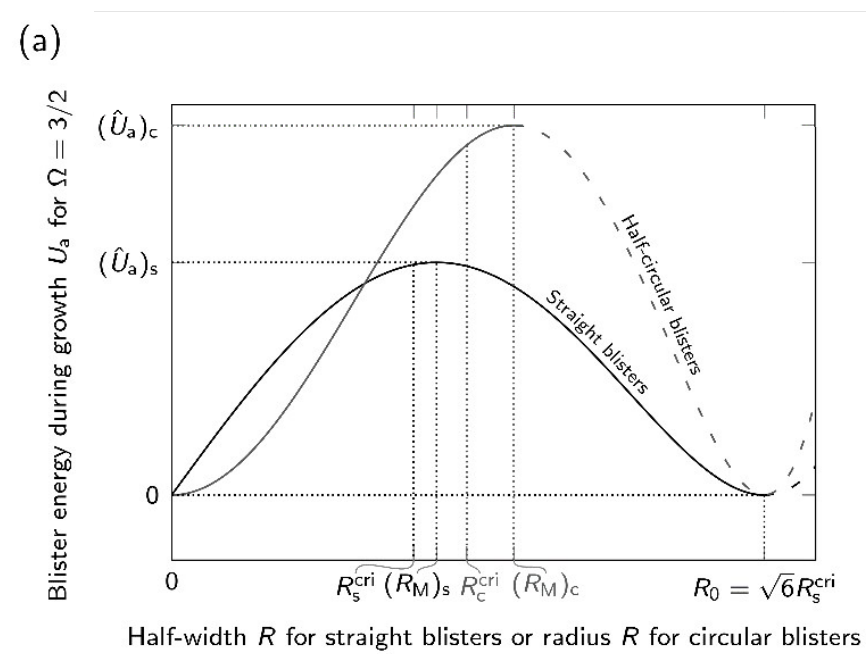

(b)

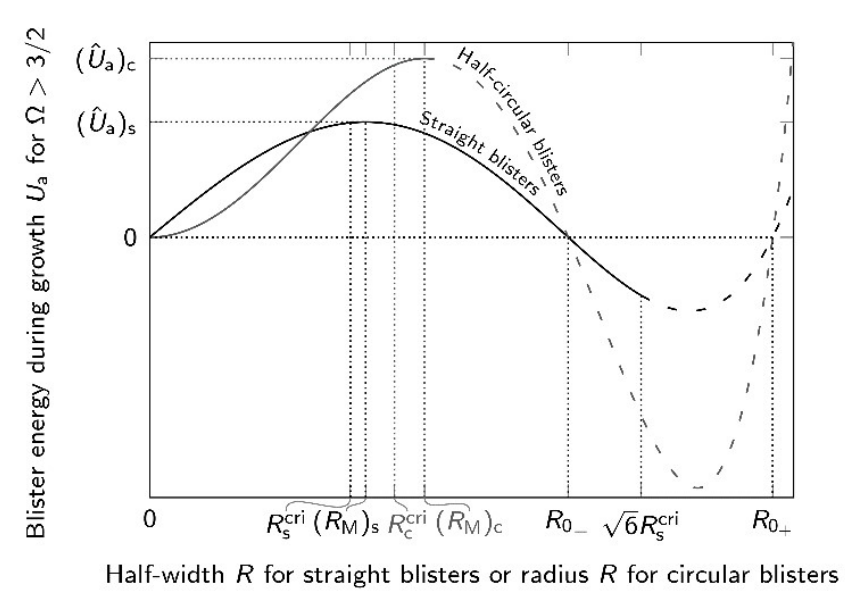

Fig. 2. The variations of $\left(U_{\mathrm{a}}\right)_{\mathrm{s}}$ and $\left(U_{\mathrm{a}}\right)_{\mathrm{c}}$ with $R$ for: (a), $\Omega=3 / 2$ and (b), $\Omega>3 / 2$.

(i) In the range $0 \leq R<R_{\mathrm{s}}^{\mathrm{cri}},\left(U_{\mathrm{a}}\right)_{\mathrm{s}}$ and $\left(U_{\mathrm{a}}\right)_{\mathrm{c}}$ increase monotonically with $R$, which indicates that an energy source such as PECs is required for the nucleation and growth of the blister. 
(ii) At $R=R_{\mathrm{s}}^{\mathrm{cri}}=\pi h /\left(2 \sqrt{3 \bar{\varepsilon}_{0}}\right)$ and $R=R_{\mathrm{c}}^{\text {cri }}=1.22 \pi h /\left(2 \sqrt{3 \bar{\varepsilon}_{0}}\right)$, conventional primary buckling occurs in the straight blister and circular blister respectively. In the range $R_{\mathrm{s}}^{\text {cri }}<R<\left(R_{\mathrm{M}}\right)_{\mathrm{s}}$, both $\left(U_{\mathrm{a}}\right)_{\mathrm{s}}$ and $\left(U_{\mathrm{a}}\right)_{\mathrm{c}}$ continue increasing with $R$. This reveals that PECs are still required to drive blister growth even though primary buckling has occurred in the straight blister.

(iii) At $R=R_{\mathrm{M}}$, the blister energy during growth reaches its maximum value, which is called the 'blister energy capacity' $\hat{U}_{\mathrm{a}}$. For the straight blister and the circular blister respectively:

$$
\left(R_{\mathrm{M}}\right)_{\mathrm{s}}=\left\{\frac{\pi^{2} \Omega}{5 \bar{\varepsilon}_{0}}\left[1-\left(1-\frac{5}{6 \Omega}\right)^{1 / 2}\right]\right\}^{1 / 2} h
$$

and

$$
\left(R_{\mathrm{M}}\right)_{\mathrm{c}}=\left\{\frac{2 \pi^{2} \Omega}{9 \bar{\varepsilon}_{0}}\left[1-\left(1-\frac{9}{8 \Omega}\right)^{1 / 2}\right]\right\}^{1 / 2} h .
$$

Eqs. (4) and (5) show that $\left(R_{\mathrm{M}}\right)_{\mathrm{s}}<\left(R_{\mathrm{M}}\right)_{\mathrm{c}}$. This indicates that the straight blister reaches its blister energy capacity faster than the half-circular blister, after which, $\left(U_{\mathrm{a}}\right)_{\mathrm{s}}$ decreases from $\left(\hat{U}_{\mathrm{a}}\right)_{\mathrm{s}}$ while $\left(U_{\mathrm{a}}\right)_{\mathrm{c}}$ continues to increase with $R$. This means that blister energy is being released from the straight blister and transmitted to the half-circular blister so that $\left(U_{\mathrm{a}}\right)_{\mathrm{c}}$ can increase to $\left(\hat{U}_{\mathrm{a}}\right)_{\mathrm{c}}$. Note that $\left(R_{\mathrm{M}}\right)_{\mathrm{s}}<R_{\mathrm{c}}^{\text {cri }}<\left(R_{\mathrm{M}}\right)_{\mathrm{c}}$, which indicates that conventional primary buckling and receiving energy from the straight blister occur simultaneously in the halfcircular blister.

(iv) Zero blister energy occurs at two values of $R$, given by $R_{0_{-}}$and $R_{0_{+}}$for both straight and circular blisters respectively:

$$
R_{0_{-}}=\left\{\frac{\pi^{2} \Omega}{3 \bar{\varepsilon}_{0}}\left[1-\left(1-\frac{3}{2 \Omega}\right)^{1 / 2}\right]\right\}^{1 / 2} h
$$

and

$$
R_{0_{+}}=\left\{\frac{\pi^{2} \Omega}{3 \bar{\varepsilon}_{0}}\left[1+\left(1-\frac{3}{2 \Omega}\right)^{1 / 2}\right]\right\}^{1 / 2} h .
$$


When $\Omega=3 / 2$, then Eqs. (6) and (7) give $R_{0_{-}}=R_{0_{+}}=R_{0}=\sqrt{6} R_{\mathrm{s}}^{\text {cri }}$, as shown in Fig. 2a.

(v) In the range $\left(R_{\mathrm{M}}\right)_{\mathrm{c}}<R<R_{0_{-}}$for $\Omega>3 / 2$, or equivalently in the range $\left(R_{\mathrm{M}}\right)_{\mathrm{c}}<R<R_{0}$ for $\Omega=3 / 2$, both $\left(U_{\mathrm{a}}\right)_{\mathrm{s}}$ and $\left(U_{\mathrm{a}}\right)_{\mathrm{c}}$ monotonically decrease with $R$. This indicates that both the straight and half-circular blisters are releasing their stored energy. Based on energy conservation, this released energy is transmitted to the TCB tip to provide the energy for forward propagation. The half-circular blister therefore develops a sharper tip where $R<\left(R_{\mathrm{M}}\right)_{\mathrm{c}}$, while the straight blister remains straight. The dashed line for the half-circular blister in Fig. 2 indicates that the original half-circular blister is no longer growing with a circular edge. This does not affect the validity of the $\Omega$ formulae, which are derived later and apply to the fully-developed region.

(vi) Secondary buckling occurs in the longitudinal direction in the straight blister at $R=\sqrt{6} R_{\mathrm{s}}^{\text {cri }}$. Secondary buckling of the straight blister changes the propagation direction of the TCB tip and generates the waviness of a TCB. The dashed line in Fig. 2 for the straight blister shows that the original blister no longer grows with straight edges. The TCB tip receives blister energy from the immediately-adjacent region and its radius is much smaller than $\left(R_{\mathrm{M}}\right)_{\mathrm{c}}$. In the range $R>\sqrt{6} R_{\mathrm{s}}^{\text {cri }}$, the blister energy for TCBs cannot be described by Eqs. (1) and (2) since the blister edges have become wavy. Nevertheless, the normal crosssection profile of TCBs (as shown in Fig. 3c) is still sinusoidal, which means that the energy balance approach in the current work is still applicable for the determination of morphology parameters. In the fully-developed TCB region, the width is $2 R_{0+}$. Details are presented in Section 2.2.

(vii) Once $R>\left(R_{\mathrm{M}}\right)_{\mathrm{c}}$, no further PEC energy is required for TCB growth. The TCB growth energy is completely supplied by the energy supplied from the region adjacent to the TCB tip. This is self-sustaining due to energy conservation: The fully-developed TCB region has zero blister energy and so the net energy requirement is zero, even though PEC energy is initially required to nucleate a TCB, which is then continually transmitted forward to the TCB for further growth.

(viii) For $\Omega \gg 3 / 2, R_{\mathrm{s}}^{\text {cri }} \approx\left(R_{\mathrm{M}}\right)_{\mathrm{s}}$ and $R_{\mathrm{c}}^{\text {cri }} \approx\left(R_{\mathrm{M}}\right)_{\mathrm{c}}$, which shows that the primary buckling happens simultaneously with the maximum blister energy for both straight and half-circular blisters. Therefore when $\Omega \gg 3 / 2$, PECs are not required to drive blister growth once primary buckling has occurred. 
The preceding qualitative discussion shows that PECs are required to nucleate and drive straight and half-circular blisters in their early-growth stages. For a TCB to develop, the blister energy capacity $\left(\hat{U}_{\mathrm{a}}\right)_{\mathrm{c}}$ of a half-circular blister at an edge, or alternatively $2\left(\hat{U}_{\mathrm{a}}\right)_{\mathrm{c}}$ for a full-circular blister in a central region, must be achieved, and the quantity $\Omega$ must not be less than $3 / 2$. Furthermore, the width of a straight blister must be greater than $\pi h / \sqrt{2 \bar{\varepsilon}_{0}}$ for secondary buckling to occur, which brings about the waviness of a TCB.

\subsection{Morphology parameters of fully-developed telephone cord blisters}

Fig. 3 shows a typical TCB in a thin film on a thick substrate where $2 R, A_{x}, A_{y}$ and $\lambda$ represent the width, height, transverse amplitude and wavelength of the TCB respectively. This part of the TCB is regarded as fully developed with no further growth. This section aims to derive analytical formulae to determine the values of the four morphology parameters. The part close to the TCB tip is regarded as the non-fully developed part.

(a)

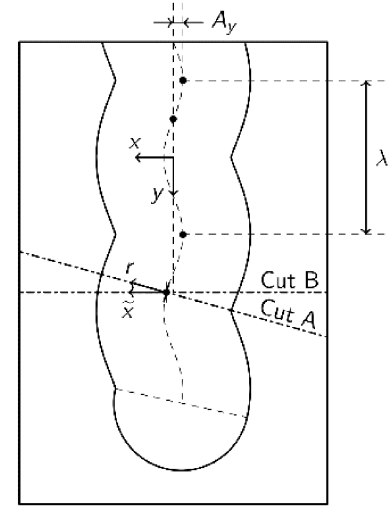

(b)

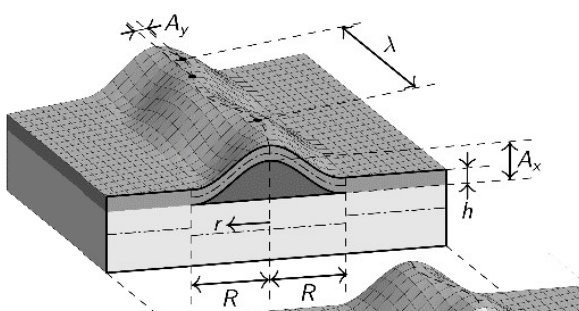

(c)

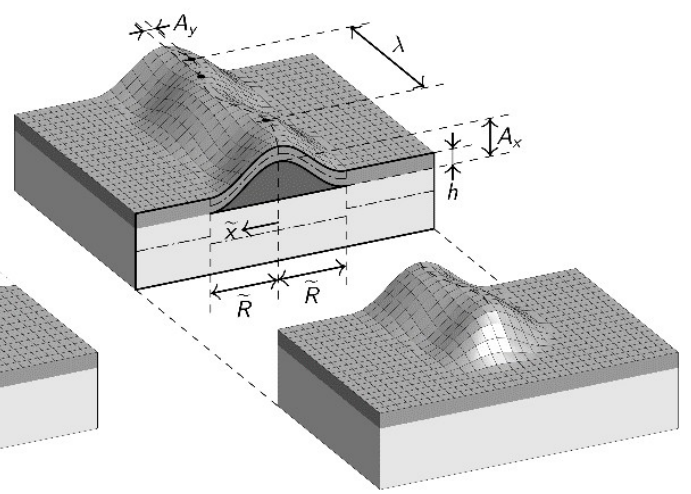

Fig. 3. A telephone cord blister. (a): Top view. (b): 3D view of cut A (shown in a) which is perpendicular to the sinusoidal centerline of the TCB. (c): 3D view of cut B (shown in a) which is parallel to the global $x$ axis.

Each narrow normal slice of the fully-developed TCB can be considered as a straight blister. By considering energy conservation, the blister energy $U_{\mathrm{a}}$ should be zero. Therefore, the TCB half-width $R=R_{0_{+}}$, or equivalently, after some manipulation of Eq. (7),

$$
\frac{R}{R_{\mathrm{c}}}=2(\Omega \bar{\Omega})^{1 / 2},
$$

where $R_{\mathrm{c}}=R_{\mathrm{s}}^{\text {cri }}$, and where 


$$
\bar{\Omega}=1+\left(1-\frac{3}{2 \Omega}\right)^{1 / 2},
$$

which varies from $\bar{\Omega}=1$ at $\Omega=3 / 2$ to $\bar{\Omega}=2$ at $\Omega \rightarrow \infty$. In Eq. (8), $R_{\mathrm{c}}$ is given by

$$
R_{\mathrm{c}}=\left[\frac{\pi^{2} E}{12\left(1-v^{2}\right) \sigma_{0}}\right]^{1 / 2} h .
$$

The TCB height $A_{x}$ during growth (i.e. the amplitude of the upward deflection of the TCB) is calculated based on Refs. $[17,18]$ with $R$ given by Eq. (8): The crack tip bending moment due to the sinusoidal normal cross-section profile (as shown in Fig. 3c) produces energy release rate which is equated to the fracture toughness, giving

$$
\frac{A_{x}}{h}=\frac{4 \Omega^{1 / 2} \bar{\Omega}}{\sqrt{3}} .
$$

Substituting $\Omega=3 / 2$ into Eqs. (11) and (8) gives the minimum values of $A_{x} / h=2 \sqrt{2}$ and $R / R_{\mathrm{c}}=\sqrt{6}$. Secondary buckling occurs in the longitudinal direction, resulting in worm-like or telephone-cord-like morphology, when $A_{x} / h>2 \sqrt{2}$ or $R / R_{\mathrm{c}}>\sqrt{6}$. Both $A_{x} / h$ and $R / R_{\mathrm{c}}$ increase with increasing $\Omega$.

The in-plane stresses are $\sigma_{x}=\sigma_{x}^{\mathrm{R}}-\sigma_{0}$ and $\sigma_{y}=\sigma_{y}^{\mathrm{R}}-\sigma_{0}$ with $\sigma_{x}^{\mathrm{R}}$ and $\sigma_{y}^{\mathrm{R}}$ being the relaxation stresses that are positive in tension. In the plane-strain condition, $\sigma_{y}^{\mathrm{R}}=v \sigma_{x}^{\mathrm{R}}$. Based on the sinusoidal normal cross-section profile and the von Kármán geometric nonlinearity assumption with $R$ given by Eq. (8), Refs. [17,18] also give

$$
\sigma_{x}^{\mathrm{R}}=\bar{\Omega} \sigma_{0} \text {. }
$$

When $\Omega=3 / 2$, then $\sigma_{x}^{R}=\sigma_{0}$. When $\Omega \gg 3 / 2$, then $\sigma_{x}^{R}$ approaches to $2 \sigma_{0}$. The halfwidth $R$, the height $A_{x}$ and the relaxation stress $\sigma_{x}^{R}$ together provide the basis to determine the wavelength $\lambda$ and transverse amplitude $A_{y}$.

An approximate calculation of the wavelength $\lambda$ is now developed. Consider a separated flat film with width $2 R$ given by Eq. (8) and length $\lambda$ with no outward deflection. The separated flat film is under in-plane stresses $\sigma_{x}=\sigma_{x}^{\mathrm{R}}-\sigma_{0}$ and $\sigma_{y}=\sigma_{y}^{\mathrm{R}}-\sigma_{0}$ with $\sigma_{x}^{\mathrm{R}}$ given by Eq. (12) and $\sigma_{y}^{\mathrm{R}}=v \sigma_{x}^{\mathrm{R}}$. The following assumed perturbed outward deflection is applied to the separated flat film: 


$$
w(x, y)=\frac{a_{x}}{2}\left[1+\cos \left(\frac{\pi}{R}\left(x-a_{y} \sin \left(\frac{2 \pi y}{\lambda}\right)\right)\right)\right],
$$

in which $a_{x}$ and $a_{y}$ are two imaginary arbitrarily-small perturbation parameters and $\lambda$ is the wavelength. A similar perturbed deflection is used in Ref. [21]. The perturbed strain energy is purely due to bending and is calculated as

$$
\partial U=\frac{1}{2} \frac{\bar{E} h^{3}}{12} \int_{-R}^{R} \int_{0}^{\lambda}\left[\left(\frac{\partial^{2} w}{\partial x^{2}}\right)^{2}+\left(\frac{\partial^{2} w}{\partial y^{2}}\right)^{2}+2 v \frac{\partial^{2} w}{\partial x^{2}} \frac{\partial^{2} w}{\partial y^{2}}+2(1-v)\left(\frac{\partial^{2} w}{\partial x \partial y}\right)^{2}\right] d y d x
$$

The perturbed potential of the in-plane stresses, $\sigma_{x}=\sigma_{x}^{\mathrm{R}}-\sigma_{0}$ and $\sigma_{y}=\sigma_{y}^{\mathrm{R}}-\sigma_{0}$, is calculated by using the von Kármán geometrical nonlinearity assumption:

$$
\partial V=\frac{1}{2} \int_{-R}^{R} \int_{0}^{\lambda}\left[\left(\frac{\partial w}{\partial x}\right)^{2} \sigma_{x}+\left(\frac{\partial w}{\partial y}\right)^{2} \sigma_{y}\right] h d y d x
$$

The total perturbed potential energy $\Pi_{p}=U+V$ is then expressed as

$$
\partial \Pi=\frac{\pi^{2} h \lambda a_{x}^{2}}{8 R}\left\{\begin{array}{l}
{\left[\frac{\pi^{2} \bar{E}}{12}\left(\frac{h}{R}\right)^{2}+\sigma_{x}\right]+} \\
\frac{\pi^{2}}{2}\left(\frac{a_{y}}{h}\right)^{2} \bar{E}\left[\left(\frac{h}{R}\right)^{2}+\left(\frac{2 h}{\lambda}\right)^{2}\right]^{2} \\
+\left[\left(\frac{h}{R}\right)^{2}+v\left(\frac{2 h}{\lambda}\right)^{2}\right] \sigma_{x}^{R} \\
-\left[\left(\frac{h}{R}\right)^{2}+\left(\frac{2 h}{\lambda}\right)^{2}\right] \sigma_{0}
\end{array}\right\} .
$$

Setting $\partial \Pi=0$ gives the primary buckling or Euler column buckling condition as

$$
\sigma_{x}=-\frac{\pi^{2} \bar{E}}{12}\left(\frac{h}{R}\right)^{2}
$$

and the secondary buckling or the TCB buckling condition as

$$
\frac{\pi^{2} \bar{E}}{12}\left[\left(\frac{h}{R}\right)^{2}+\left(\frac{2 h}{\lambda}\right)^{2}\right]^{2}+\left[\left(\frac{h}{R}\right)^{2}+v\left(\frac{2 h}{\lambda}\right)^{2}\right] \sigma_{x}^{R}-\left[\left(\frac{h}{R}\right)^{2}+\left(\frac{2 h}{\lambda}\right)^{2}\right] \sigma_{0}=0 .
$$

Since the magnitude of first term in Eq. (18) is usually one order smaller than the magnitudes of the other two terms, then, by neglecting the first term, Eq. (18) gives the global TCB wavelength as 


$$
\frac{\lambda}{2 R}=\left(\frac{v \sigma_{x}^{\mathrm{R}}-\sigma_{0}}{\sigma_{0}-\sigma_{x}^{\mathrm{R}}}\right)^{1 / 2} .
$$

Substituting Eq. (12) into Eq. (19) gives

$$
\frac{\lambda}{2 R}=\left(\frac{1-\bar{\Omega}}{\bar{\Omega}-1}\right)^{1 / 2} .
$$

Eq. (20) shows that the transition from a straight blister to a TCB occurs at $\Omega=3 / 2$ where the wavelength $\lambda$ approaches infinity. Eq. (20) also shows that $\lambda / 2 R$ decreases with increasing $\Omega$ and Poisson's ratio $v$.

Now, an approximate method is developed to determine the transverse amplitude $A_{y}$. With the TCB growing along the global $y$ axis, as shown in Fig. 3a, the TCB shape is assumed to be in the following sinusoidal form:

$$
w(x, y)=\frac{A_{x}}{2}\left[1+\cos \left(\frac{\pi \tilde{x}}{\tilde{R}}\right)\right]=\frac{A_{x}}{2}\left[1+\cos \left(\frac{\pi}{\tilde{R}}\left(x-A_{y} \sin \frac{2 \pi y}{\lambda}\right)\right)\right],
$$

where $\tilde{R}$ is the distance from the TCB sinusoidal centerline to the crack tips as shown in Fig. 3c, and $\tilde{x}$ is the local axis, parallel to the global $x$ axis, as shown in Fig. 3a and c, defined as

$$
\tilde{x}=x-A_{y} \sin \left(\frac{2 \pi y}{\lambda}\right) .
$$

The sinusoidal centerline of the TCB is represented by $\tilde{x}=0$, that is,

$$
x=A_{y} \sin \left(\frac{2 \pi y}{\lambda}\right)
$$

The variable $\tilde{R}$ varies along the length and is related to the half-width $R$ approximately by

$$
\tilde{R} \approx\left[1+\left(\frac{d x}{d y}\right)^{2}\right]^{1 / 2} R \approx\left[1+\frac{1}{2}\left(\frac{d x}{d y}\right)^{2}\right] R
$$

The average value of the second term over a wavelength is $\pi A_{y} / \lambda$. An approximation for $\tilde{R}$ is therefore taken as

$$
\tilde{R}=\left[1+\left(\frac{\pi A_{y}}{\lambda}\right)^{2}\right] R=\bar{A}_{y} R
$$


When the transverse amplitude-to-wavelength ratio $A_{y} / \lambda$ is less than approximately $1 / 10$, Eqs. (24) and (25) have high accuracy; otherwise, significant inaccuracy can occur as shown in Section 3.

The in-plane strains in the TCB are

$$
\begin{aligned}
& \varepsilon_{x}=-\varepsilon_{0}-z \frac{\partial^{2} w}{\partial x^{2}}+\frac{1}{2}\left(\frac{\partial w}{\partial x}\right)^{2} \\
& \varepsilon_{y}=-\varepsilon_{0}-z \frac{\partial^{2} w}{\partial y^{2}}+\frac{1}{2}\left(\frac{\partial w}{\partial y}\right)^{2}
\end{aligned}
$$

and

$$
\gamma_{x y}=-2 z \frac{\partial^{2} w}{\partial x \partial y}+\frac{\partial w}{\partial x} \frac{\partial w}{\partial y}
$$

where $\varepsilon_{0}=(1-v) \sigma_{0} / E$ is the residual compressive strain. The bending strain energy is therefore

$$
U_{\mathrm{b}}=\frac{1}{2} \frac{\bar{E} h^{3}}{12} \int_{-\tilde{R}}^{\tilde{R}} \int_{0}^{\lambda}\left[\left(\frac{\partial^{2} w}{\partial x^{2}}\right)^{2}+\left(\frac{\partial^{2} w}{\partial y^{2}}\right)^{2}+2 v \frac{\partial^{2} w}{\partial x^{2}} \frac{\partial^{2} w}{\partial y^{2}}+2(1-v)\left(\frac{\partial^{2} w}{\partial x \partial y}\right)^{2}\right] d y d \tilde{x},
$$

and the in-plane strain energy is

$$
U_{\mathrm{i}}=\int_{-\tilde{R}}^{\tilde{R}} \int_{0}^{\lambda}\left\{\begin{array}{l}
\frac{1}{8} \bar{E}\left[\left(\frac{\partial w}{\partial x}\right)^{4}+\left(\frac{\partial w}{\partial y}\right)^{4}+2\left(\frac{\partial w}{\partial x}\right)^{2}\left(\frac{\partial w}{\partial y}\right)^{2}\right] \\
-\frac{1}{2}\left[\left(\frac{\partial w}{\partial x}\right)^{2}+\left(\frac{\partial w}{\partial y}\right)^{2}\right] \\
\sigma_{0}+\frac{1-v}{E} \sigma_{0}^{2}
\end{array}\right\}
$$

and the interface fracture energy is

$$
U_{\mathrm{s}}=\int_{-\tilde{R}}^{\tilde{R}} \int_{0}^{\lambda} G_{\mathrm{c}} d y d \tilde{x}=2 \tilde{R} \lambda G_{\mathrm{c}} .
$$

Conservation of energy requires that

$$
U_{\mathrm{b}}+U_{\mathrm{i}}+U_{\mathrm{s}}=2 \tilde{R} \lambda h \frac{1-v}{E} \sigma_{0}^{2} .
$$

Substituting Eqs. (21), (29), (30) and (31) into Eq. (32) gives the following equation: 


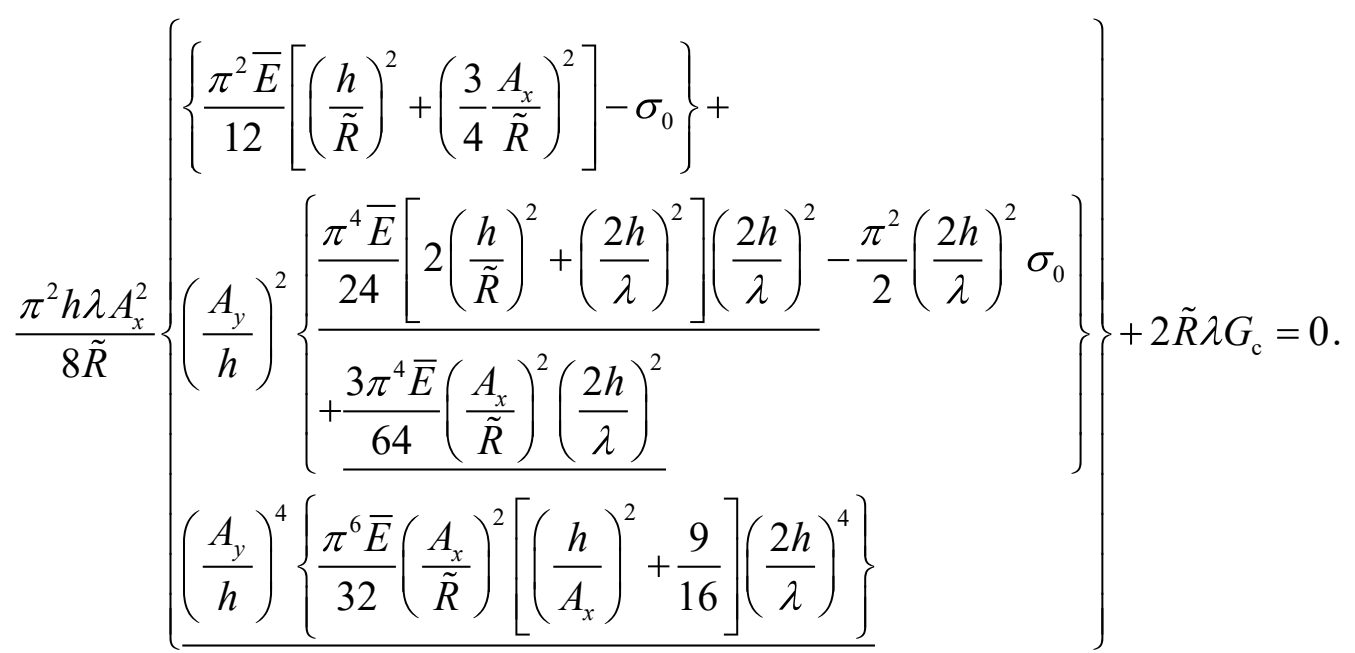

Neglecting the underlined higher-order terms leads to

$$
\frac{\pi^{2}}{12}\left[\left(\frac{h}{\tilde{R}}\right)^{2}+\left(\frac{3}{4} \frac{A_{x}}{\tilde{R}}\right)^{2}\right]+\frac{16}{\pi^{2}}\left(\frac{\tilde{R}}{A_{x}}\right)^{2} \frac{G_{c}}{\bar{E} h}-\left[1+2\left(\frac{\pi A_{y}}{\lambda}\right)^{2}\right] \bar{\varepsilon}_{0}=0
$$

Substituting $\tilde{R}$ in Eq. (25) into Eq. (34) gives

$$
\frac{\pi^{2}}{12}\left[\left(\frac{h}{R}\right)^{2}+\left(\frac{3}{4} \frac{A_{x}}{R}\right)^{2}\right]+\bar{A}_{y}^{2}\left[\frac{16}{\pi^{2}}\left(\frac{R}{A_{x}}\right)^{2} \frac{G_{c}}{\bar{E} h} \bar{A}_{y}^{2}-\left(2 \bar{A}_{y}-1\right) \bar{\varepsilon}_{0}\right]=0 .
$$

Eq. (35) can be further simplified by using Eqs. (8) and (10), which gives

$$
1+3 \Omega \bar{\Omega}^{2}+2 \bar{A}_{y}^{2}\left[\bar{A}_{y}^{2}-2 \Omega \bar{\Omega}\left(2 \bar{A}_{y}-1\right)\right]=0
$$

where

$$
A_{y}=\left(\bar{A}_{y}-1\right)^{1 / 2} \frac{\lambda}{\pi}
$$

An iterative method can be used to determine $\bar{A}_{y}$ and then $A_{y}$. It is easy to verify that $A_{y}>0.0930 \lambda$ if $\Omega>3 / 2$ and that the maximum value is $A_{y}=0.1053 \lambda$ for $\Omega \gg 3 / 2$. Now all four morphology parameters, that is the width $2 R$, height $A_{x}$, transverse amplitude $A_{y}$ and the wavelength $\lambda$, can be determined.

The above formulae are called the ' $\Omega$ formulae' in this work and their validity for predicting the formation, morphology, residual stress and interface fracture toughness of TCBs will be examined by using extensive independent experimental data $[9,12,19,22-34]$ in Section 3.

Finally, it is worth noting that the above development applies equally to the mixed-mode fracture partition theories based on classical plate theory [17,18,35-39], first-order shear- 
deformable plate theory $[17,18,35-39]$ and $2 \mathrm{D}$ elasticity $[17,18,35,40,41]$. The phase angles $\psi=\arctan \left(G_{\mathrm{II}} / G_{\mathrm{I}}\right)^{1 / 2}$ of the mixed-mode fracture here are independent of the blister width or radius under the developed theory and are calculated as $0^{\circ}, 60^{\circ}$ and $37.9^{\circ}$ for these three mixed-mode fracture partition theories respectively [17,18]. When using the linear propagation criterion, the respective interface fracture toughness $G_{\mathrm{c}}$ is

$$
G_{\mathrm{c}}=G_{\mathrm{Ic}}
$$

for the classical plate theory, or

$$
G_{\mathrm{c}}=\frac{4}{1+3 \Lambda} G_{\mathrm{Ic}}
$$

for first-order shear-deformable plate theories respectively, or

$$
G_{\mathrm{c}}=\frac{1}{0.6227+0.3773 \Lambda} G_{\mathrm{Ic}}
$$

for $2 \mathrm{D}$ elasticity. The interface mode I fracture toughness is $G_{\mathrm{Ic}}$, and the mode II fracture toughness is $G_{\text {IIc }}=G_{\text {Ic }} / \Lambda$. The $2 \mathrm{D}$ elasticity partition theory is used in the present study since Refs. [17,18] have demonstrated that it gives the most accurate predictions for thin film interface fracture.

Note that in Section $3, G_{\mathrm{c}}$ is obtained by using the measured blister width and residual stress. In general, $G_{\mathrm{c}}$ can be obtained from any two measured blister morphology parameters. By this approach, any of the mixed-mode fracture partition theories give the same $G_{\mathrm{c}}$ value, and consequently the same values for the remaining TCB morphology parameters. If, however, $G_{\mathrm{Ic}}$ and $G_{\mathrm{IIc}}$ are specified individually to determine the overall $G_{\mathrm{c}}$, then the TCB morphology parameters do then depend on the mixed-mode fracture partition theory, as each one will give a different $G_{\mathrm{c}}$ value.

\section{Experimental validation}

The $\Omega$ formulae above are now validated by using the various independent experimental measurements of TCB morphology reported in the literature, which are tabulated in Appendix B.

The condition of TCB formation, namely, that $\Omega>3 / 2$ from Eq. (3), or equivalently, that $A_{x} / h>2 \sqrt{2}$ from Eq. (11), is examined first using experimental data from Refs. 
$[9,12,19,22,24,28,30,31,33]$. As shown in Fig. 4, all the measurement data are above the horizontal dotted line representing $A_{x} / h=2 \sqrt{2}$ except for one [24]. This one exception lies just on the line and so represents the point of transition from a straight blister to a TCB. It is worth noting that the conventional buckling-driven approach [5] requires that $v>0.255 \pm 0.001$ which is the vertical dashed line in Fig. 4. It is clearly seen that one measurement [28] does not satisfy this condition.

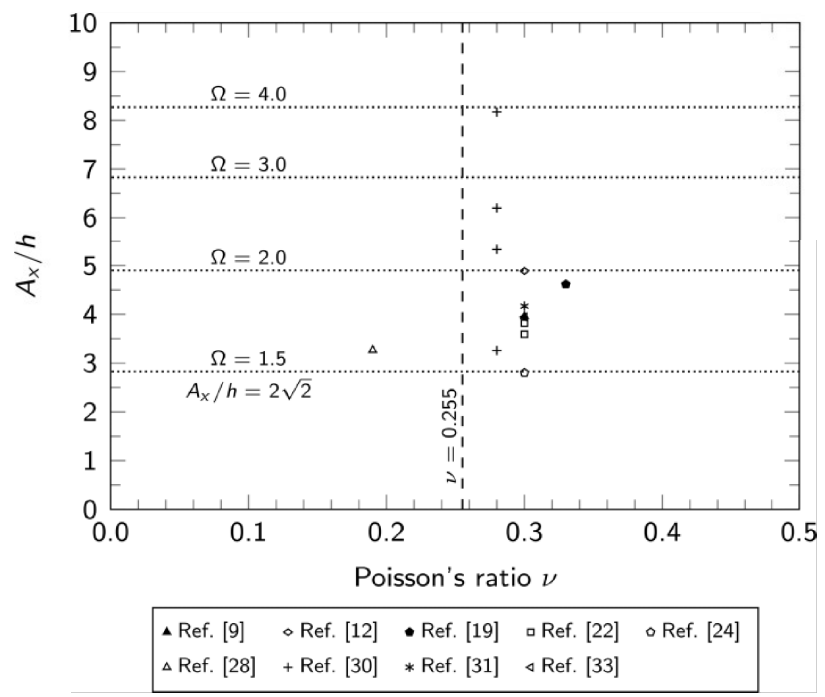

Fig. 4. Validation of the condition of TCB formation, namely, that $\Omega>3 / 2$ from Eq. (3), or equivalently, that $A_{x} / h>2 \sqrt{2}$ from Eq. (11).

In the second exercise, the accuracy of Eqs. (8) and (11) is examined for predicting the two local morphology parameters, namely, the TCB half-width $R$ and height $A_{x}$, by using experimental data from Refs. [12,19,24,31]. Since Eq. (8) involves both the measured TCB half-width $R$ and the residual stress $\sigma_{0}$, this exercise also examines the accuracy of the developed theory for the prediction of residual stress $\sigma_{0}$ in the film. The results are shown in Fig. 5. It is seen that the experimental data are in an excellent agreement with the predictions of the PEC-driven approach, shown as the solid curve, and are far away from the bucklingdriven straight blister model [40], shown as the dashed line. The buckling-driven pinnedcircular model [5] is shown in Fig. 5 for $v=0.3$, but it should be noted that the curve is not particularly sensitive to Poisson's ratio. Although the buckling-driven pinned-circular blister model [9], shown as the dash-dotted line, gives improved predictions, particularly in the region where $\Omega$ is close to $3 / 2$, its predictions are still significantly far from the experimental measurements. It is worth noting that the conventional buckling-driven 
approach [5] requires that $R / R_{\mathrm{c}}>\sqrt{6.5}$ which is the vertical dashed line in Fig. 5. It is clearly seen that one measurement [24] does not satisfy this condition. Conversely, the PECdriven approach requires that $R / R_{\mathrm{c}}>\sqrt{6}$ which is the vertical dotted line in Fig. 5, and all the measurement data obey this condition.

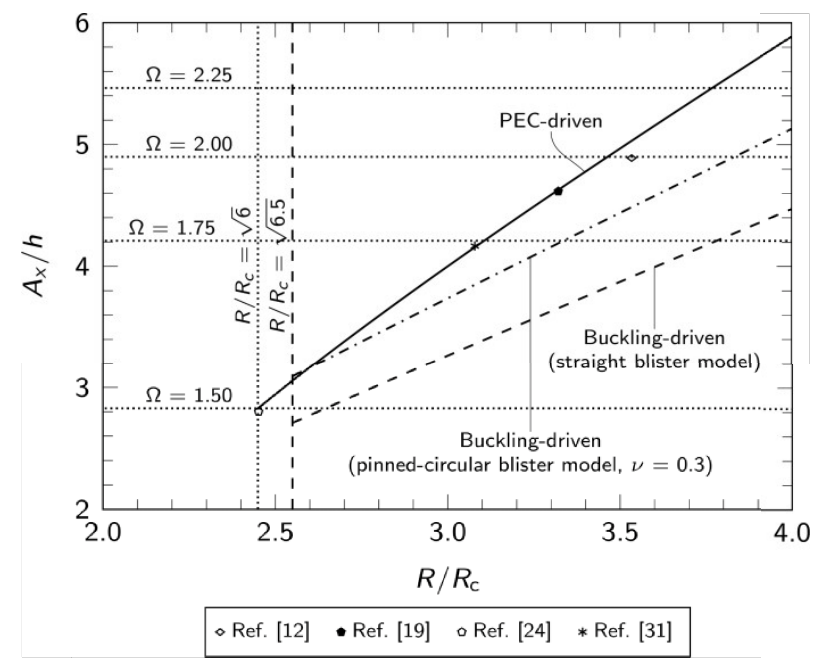

Fig. 5. Validation of Eqs. (8) and (11) for predicting the two local morphology parameters, namely, the TCB half-width $R$ and height $A_{x}$.

Fig. 5 also clearly shows that the residual stress $\sigma_{0}$ is accurately predicted by the PECdriven approach while the two buckling-driven approaches, particularly the buckling-driven straight blister model [40], make severe overestimates. Since the buckling-driven approaches are unable to predict residual stress $\sigma_{0}$, it is reasonable to expect they are also unable to predict the interface fracture toughness $G_{\mathrm{c}}$. Conversely, it is reasonable to expect that the PEC-driven approach can also accurately predict the interface fracture toughness $G_{\mathrm{c}}$. A detailed examination will be presented in Table 2 later.

In the next exercise, the variation of $\lambda /(2 R)$ from Eq.(20), in which the TCB wavelength $\lambda$ is a global morphology parameter, is examined. First, its variation with respect to Poisson's ratio $v$ and $\Omega$ is considered using the experimental results from Refs. $[9,12,22,23,26,27,29,30,32-34]$ in Fig. 6. The buckling-driven approach [5,40] predicts that $\lambda /(2 R)=0.95$, shown as the horizontal dashed line. This clearly disagrees with the experiment measurements in Refs. [9,12,22,23,26,27,29,30,32-34]. In contrast, the PECdriven approach predicts via Eq. (20) that $\lambda /(2 R)$ decreases with increasing $\Omega$ and Poisson's 
ratio $v$. It is worth noting again that TCBs can indeed occur when the Poisson's ratio $v$ is smaller than $v=0.255 \pm 0.001$, shown as the vertical dashed line in Fig. 6, which also breaks the requirement of the conventional buckling-driven approach $[5,40]$.

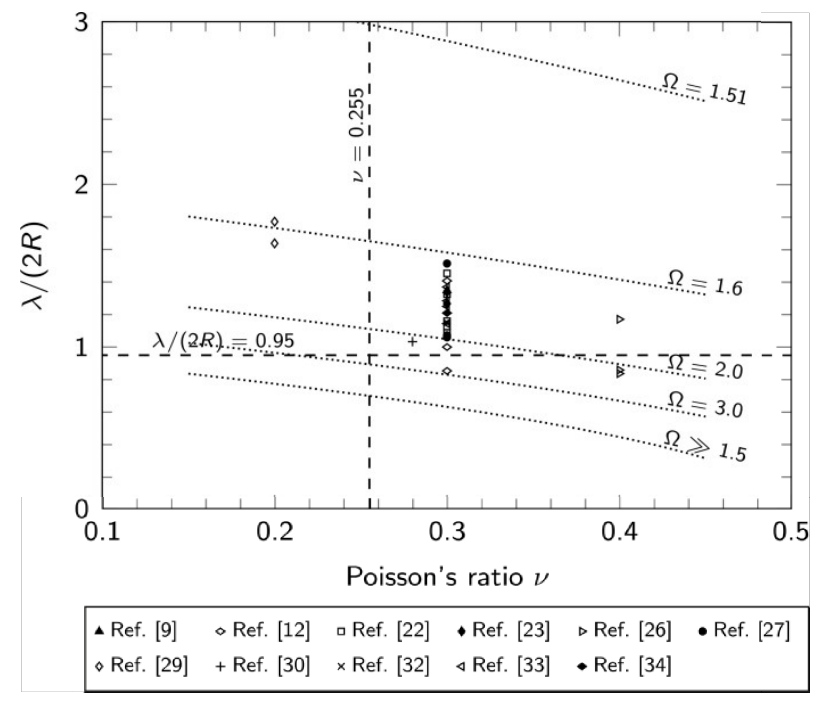

Fig. 6. Variation of $\lambda /(2 R)$, given by Eq. (20), with respect to Poisson's ratio $v$ and $\Omega$.

To validate Eq. (20), an additional comparison is made in Fig. 7 using the experimental measurements of TCB half-width $R$, height $A_{x}$ and wavelength $\lambda$ from Refs. $[9,12,22,30,33]$. The Poisson's ratio $v$ of the films in Refs. $[9,12,22,33]$ is 0.3 and it is 0.28 in Ref. [30]. It is seen that measured experimental data lie close to the solid curve which represents the PEC-driven approach.

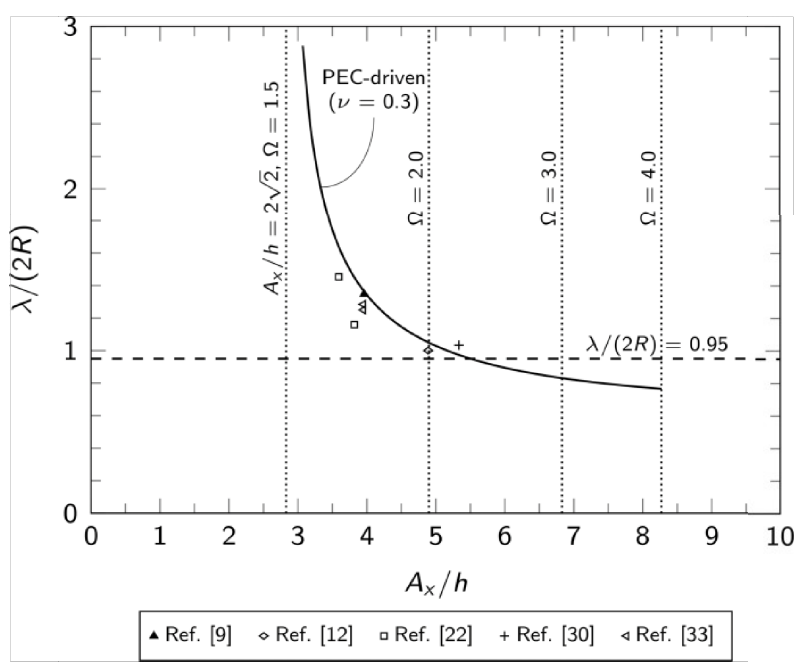

Fig. 7. Validation of Eq. (20) for predicting the wavelength $\lambda$, which is a global morphology parameter. 
In the fourth exercise, the accuracy of Eq. (36) is examined for predicting the TCB transverse amplitude $A_{y}$, which is the other global morphology parameter, by using experimental data from Refs. [9,12,22,23,25-27,29,30,32-34]. The results are shown in Fig. 8. Several observations are worthy of discussion: (1) Most of the experimental data fall in or close to the region $0.0930 \lambda<A_{y}<0.1053 \lambda$ corresponding to $1.5<\Omega<\infty$, as predicted by Eq.(36); (2) The experimental data in the region $0.0930 \lambda<A_{y}<0.1053 \lambda$ follow Eq. (36) well; (3) Two data points from Ref. [23] lie far below the predicted region. This is because these two TCBs have not yet developed fully. In contrast, the other data point from Ref. [23], which does represent a fully-developed TCB, does indeed lie inside the predicted the region; (4) One data point from Ref. [25] lies far above the predicted region. This is because this TCB is not sinusoidal, and has a very large transverse amplitude $A_{y}$. It can therefore be concluded that Eq. (36) is able to give good predictions for the transverse amplitude $A_{y}$ of fully-developed sinusoidal TCBs.

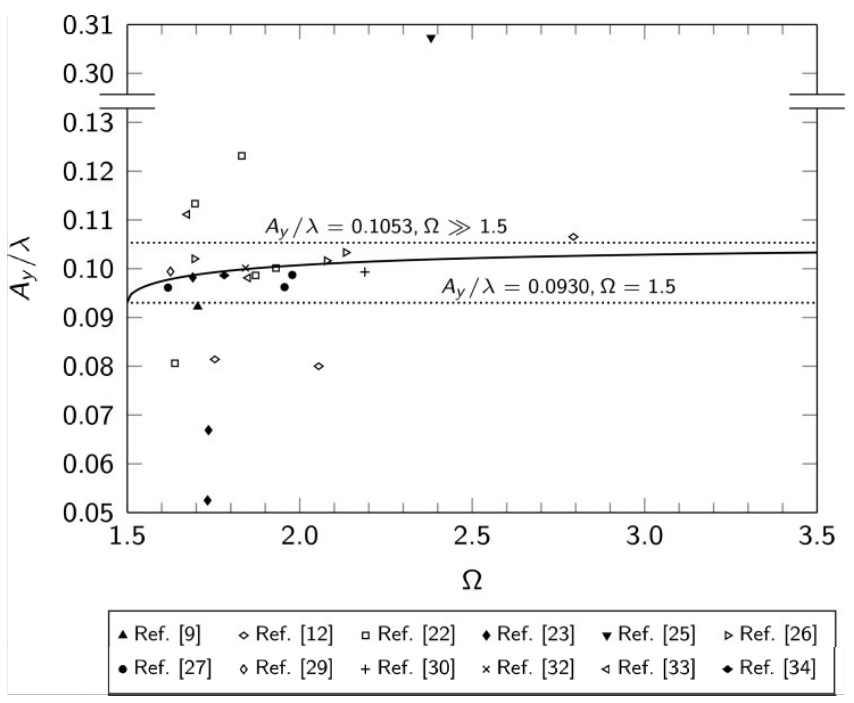

Fig. 8. Validation of Eq. (36) for predicting the transverse amplitude $A_{y}$, which is a global morphology parameter.

Further evaluation of the $\Omega$ formulae in Eqs. (3), (11), (20) and (36) is now made by using tabulated numerical values to assess their accuracy more precisely. Two specific examples are considered for this purpose. The first example is from Ref. [9], in which diamond-like carbon film is deposited on glass substrate. The film thickness is $h=0.13 \mu \mathrm{m}$, and the Young's modulus and Poisson's ratio are $E=120 \mathrm{GPa}$ and $v=0.3$ respectively. The TCB morphology was measured at three different locations in the fully-developed region of the 
TCB, which are shown in Fig. 9a. The TCB width $2 R$ and height $A_{x}$ were measured from Fig. 9b. These measurements also provided the scale at each location for making measurements directly from Fig. 9a. The TCB wavelength $\lambda$ and transverse amplitude $A_{y}$ were measured directly from Fig. 9a using the aforementioned scales. The measurements of TCB width $2 R$ and wavelength $\lambda$ were used in Eq. (20) to calculate the corresponding $\Omega$ values. The TCB height $A_{x}$ and transverse amplitude $A_{y}$ were then predicted using Eqs. (11) and (36) respectively. Comparisons between the theoretical predictions and the experimental measurements are shown in Table 1. It is seen that the predicted $A_{x}$ and $A_{y}$ are in excellent agreement with the experimental measurements.

(a)

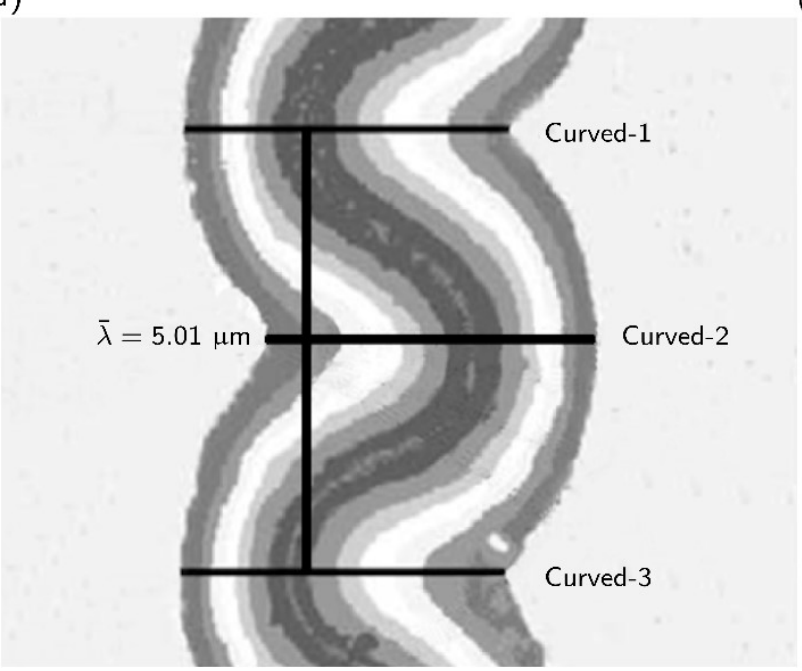

(b)

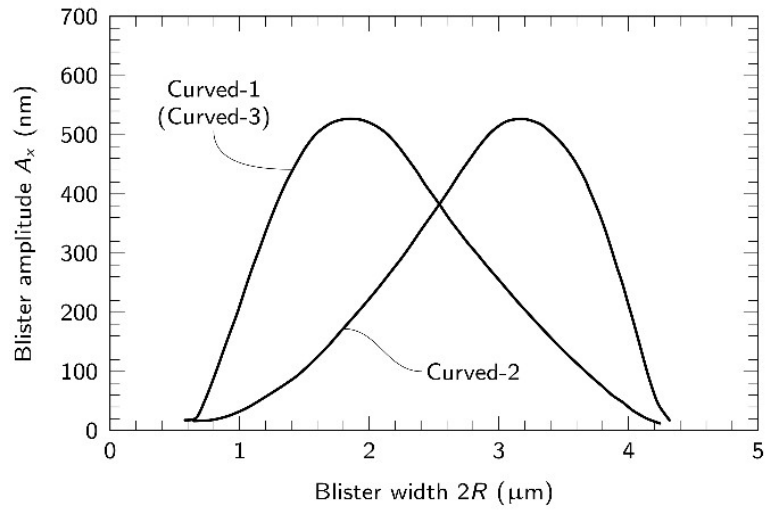

Fig. 9. Telephone cord blister morphology measurements from Ref. [9]. (a) Measurements locations. (b) Blister profiles.

Table 1. Theoretical predictions and experimental measurements of TCB morphology parameters in Refs. $[9,30]$.

\begin{tabular}{|c|c|c|c|c|c|c|c|c|}
\hline \multirow{2}{*}{ Ref. } & & \multicolumn{3}{|c|}{ Theoretical predictions (PEC-driven) } & \multicolumn{4}{|c|}{ Experimental measurements } \\
\hline & & $\Omega$ & $\mathrm{A}_{\mathrm{x}}$ or $\lambda[\mu \mathrm{m}]$ & $\mathrm{A}_{\mathrm{y}}[\mu \mathrm{m}]$ & $2 \mathrm{R}[\mu \mathrm{m}]$ & $\lambda[\mu \mathrm{m}]$ & $\mathrm{A}_{\mathrm{x}}[\mu \mathrm{m}]$ & $\mathrm{A}_{\mathrm{y}}[\mu \mathrm{m}]$ \\
\hline \multirow{4}{*}{ [9] } & Curved-1 & 1.674 & $0.514\left(\mathrm{~A}_{\mathrm{x}}\right)$ & 0.49 & 3.64 & 4.98 & 0.527 & 0.48 \\
\hline & Curved-2 & 1.690 & $0.521\left(\mathrm{~A}_{\mathrm{x}}\right)$ & 0.52 & 3.80 & 5.08 & 0.527 & 0.45 \\
\hline & Curved-3 & 1.674 & $0.514\left(\mathrm{~A}_{\mathrm{x}}\right)$ & 0.49 & 3.64 & 4.98 & 0.527 & 0.48 \\
\hline & Average & 1.679 & $0.516\left(\mathrm{~A}_{\mathrm{x}}\right)$ & 0.50 & 3.69 & 5.01 & 0.527 & 0.47 \\
\hline \multirow{3}{*}{ [30] } & Straight & 2.000 & $40.49(\lambda)$ & 4.08 & 37.60 & 40.09 & 1.47 & 3.98 \\
\hline & Curved & 2.399 & $37.87(\lambda)$ & 3.86 & 40.00 & 40.09 & 1.73 & 3.98 \\
\hline & Average & 2.200 & $39.18(\lambda)$ & 3.97 & 38.80 & 40.09 & 1.60 & 3.98 \\
\hline
\end{tabular}


The second example is from Ref. [30]. The thin film is tungsten and the substrate is silica. The film thickness is $h=300 \mathrm{~nm}$, and the Young's modulus and Poisson's ratio are $E=411 \mathrm{GPa}$ and $v=0.28$ respectively. By using the measured values of TCB width $2 R$ and height $A_{x}$ from Ref. [30], the $\Omega$ value at each location is calculated with Eq. (11), and the TCB wavelength $\lambda$ and transverse amplitude $A_{y}$ are then predicted then by Eqs. (20) and (36) respectively. It is seen from Table 1 that the predicted $\lambda$ and $A_{y}$ are again in excellent agreement with the experimental measurements in Ref. [30].

Attention is now turned to the prediction of residual stress $\sigma_{0}$ in the film and interface fracture toughness $G_{\mathrm{c}}$ by using measured morphology parameters. Table 2 corresponds to Fig. 5, and records the predicted residual stress $\sigma_{0}$ based on the measured TCB height $A_{x}$, width $2 R$ in Refs. $[12,19,24,31]$ and wavelength $\lambda$ in Ref. [12]. It is seen that the PECdriven approach gives excellent predictions. In contrast, the buckling-driven straight blister model gives severe overestimations. The pinned-circular blister approach also gives significant overestimates when $\Omega$ is not close to $3 / 2$.

Table 2. Theoretical predictions and experimental measurements of residual stress in Refs. $[12,19,24,31]$.

\begin{tabular}{|c|c|c|c|c|c|c|c|c|c|c|}
\hline \multirow[b]{4}{*}{ Ref. } & \multirow[b]{4}{*}{$\begin{array}{l}\mathrm{h} \\
{[\mu \mathrm{m}]}\end{array}$} & \multirow[b]{4}{*}{$\begin{array}{l}\mathrm{E} \\
{[\mathrm{GPa}]}\end{array}$} & \multirow[b]{4}{*}{$v$} & \multicolumn{3}{|c|}{ Experimental measurements } & \multicolumn{4}{|c|}{ Theoretical predictions } \\
\hline & & & & \multirow[b]{3}{*}{$\begin{array}{l}A_{x} \text { or } \lambda \\
{[\mu \mathrm{m}]}\end{array}$} & \multirow[b]{3}{*}{$\begin{array}{l}2 \mathrm{R} \\
{[\mu \mathrm{m}]}\end{array}$} & \multirow[b]{3}{*}{$\begin{array}{l}\sigma_{0} \\
{[\mathrm{GPa}]}\end{array}$} & \multicolumn{2}{|c|}{ PEC-driven } & \multirow{3}{*}{$\begin{array}{l}\text { Buckling- } \\
\text { driven } \\
\text { (straight } \\
\text { blister } \\
\text { model) } \\
\sigma_{0}[\mathrm{GPa}]\end{array}$} & \multirow{3}{*}{$\begin{array}{l}\begin{array}{l}\text { Buckling- } \\
\text { driven }\end{array} \\
\text { (pinned- } \\
\text { circular } \\
\text { blister } \\
\text { model) } \\
\sigma_{0}[\mathrm{GPa}]\end{array}$} \\
\hline & & & & & & & & & & \\
\hline & & & & & & & $\Omega$ & $\begin{array}{l}\sigma_{0} \\
{[\mathrm{GPa}]}\end{array}$ & & \\
\hline [24] & 0.300 & 150.0 & 0.30 & $0.84\left(\mathrm{~A}_{\mathrm{x}}\right)$ & 14.40 & 1.414 & 1.500 & 1.412 & 1.619 & 1.301 \\
\hline [31] & 0.300 & 171.8 & 0.288 & $1.25\left(\mathrm{~A}_{\mathrm{x}}\right)$ & 22.93 & 1.000 & 1.737 & 1.003 & 1.479 & 1.150 \\
\hline [19] & 0.130 & 186.0 & 0.33 & $0.60\left(\mathrm{~A}_{\mathrm{x}}\right)$ & 16.00 & 0.500 & 1.889 & 0.498 & 0.770 & 0.600 \\
\hline [12] & 0.225 & 175.0 & 0.30 & $\begin{array}{l}1.10\left(\mathrm{~A}_{\mathrm{x}}\right) \\
20.00(\lambda)\end{array}$ & $\begin{array}{l}20.00 \\
20.00\end{array}$ & $\begin{array}{l}1.000 \\
1.000\end{array}$ & $\begin{array}{l}1.996 \\
2.113\end{array}$ & $\begin{array}{l}0.958 \\
1.041\end{array}$ & $\begin{array}{l}1.515 \\
-\end{array}$ & $\begin{array}{l}1.172 \\
-\end{array}$ \\
\hline
\end{tabular}

Finally, the $\Omega$ formulae in Eqs. (3), (11), (20) and (36) are examined for their capability to predict the interface fracture toughness using the measured morphology parameters. As shown in the previous comparison in Table 2, the PEC-driven approach gives excellent predictions of the residual stress $\sigma_{0}$. Now these experimental results are used again to predict the fracture toughness. Following the PEC-driven approach, the $\Omega$ value is calculated using Eq. (8) with the measured blister width $2 R$ and residual stress $\sigma_{0}$. The fracture toughness is 
then calculated using Eq. (3). The fracture toughness is also calculated using the two buckling-driven approaches (the straight blister model, and pinned circular blister model). The results of all three approaches are presented in Table 3. Several points are worthy of discussion:

(1) The PEC-driven approach and the buckling-driven straight blister model give the smallest and the largest predictions of interface fracture toughness respectively.

(2) The mode I and II toughness, $G_{\text {Ic }}$ and $G_{\text {IIc }}$, are not available in Refs. [12,19,24,31], so it is not possible to conclude which of the theoretical predictions are in best agreement with experimental test data.

(3) The numerical simulations in Ref. [25], however, use $G_{\text {Ic }}=0.176 u_{0}$ and $G_{\text {IIc }}=28.5 u_{0}$ with $u_{0}=(1-v) \sigma_{0}^{2} h / E$ and achieve good agreement with experimentally-observed TCB shapes. They are therefore taken to be the measured values for Ref. [25] only.

(4) The PEC-driven approach predicts a constant phase angle of $\psi=37.9^{\circ}$ where $\psi=\arctan \left(G_{\mathrm{II}} / G_{\mathrm{I}}\right)^{1 / 2}$. For Ref. [25] only, the fracture toughness can therefore also be calculated using the linear propagation criterion $G_{\mathrm{c}}=G_{\mathrm{Ic}}\left[1+(\Lambda-1) \sin ^{2} \psi\right]^{-1}$ with $\psi=37.9^{\circ}$. For Ref. [25], the first value (top row) of the fracture toughness is the one calculated by Eq. (1); the second value is from the linear propagation criterion. A third way to calculate the fracture toughness is by using the nonlinear propagation criterion $G_{\mathrm{c}}=G_{\text {Ic }}\left[1+(1-\Lambda) \tan ^{2} \psi\right]^{-1}$. This is the third value (bottom row) of Ref. [25]. The $\Omega$ formula in Eq. (1) is in excellent agreement with the two fracture toughness values calculated using propagation criteria.

(5) Based on the measured blister width $2 R$ and residual stress $\sigma_{0}$, the buckling-driven straight blister and pinned-circular blister approaches predict phase angles of $\psi=79.4^{\circ}$ and $\psi=83.2^{\circ}$ respectively. For Ref. [25], the first value (top row) of the fracture toughness is the one calculated directly from the respective approaches. The second and third values are calculated using the linear and nonlinear propagation criteria respectively. These three fracture toughness values are completely different from each other.

(6) It is therefore reasonable to conclude that the PEC-driven approach gives correct predictions for the interface fracture toughness while the buckling-driven approaches cannot. 
Table 3. Theoretical predictions and experimental measurements of interface fracture toughness in Refs. [12,19,24,25,31].

\begin{tabular}{|c|c|c|c|c|c|c|c|c|c|c|c|}
\hline \multirow[b]{4}{*}{ Ref. } & \multirow[b]{4}{*}{$\begin{array}{l}\mathrm{h} \\
{[\mu \mathrm{m}]}\end{array}$} & \multirow[b]{4}{*}{$\begin{array}{l}\mathrm{E} \\
\text { [GPa] }\end{array}$} & \multirow[b]{4}{*}{$v$} & \multicolumn{4}{|c|}{ Experimental measurements } & \multicolumn{4}{|c|}{ Theoretical predictions } \\
\hline & & & & \multirow[b]{3}{*}{$\begin{array}{l}2 \mathrm{R} \\
{[\mu \mathrm{m}]}\end{array}$} & \multirow[b]{3}{*}{$\begin{array}{l}\sigma_{0} \\
{[\mathrm{GPa}]}\end{array}$} & \multirow[b]{3}{*}{$\begin{array}{l}\mathrm{G}_{\mathrm{Ic}} \\
{[\mathrm{N} / \mathrm{m}]}\end{array}$} & \multirow[b]{3}{*}{$\begin{array}{l}\mathrm{G}_{\mathrm{IIc}} \\
{[\mathrm{N} / \mathrm{m}]}\end{array}$} & \multicolumn{2}{|c|}{ PEC-driven } & \multirow{3}{*}{$\begin{array}{l}\text { Buckling- } \\
\text { driven } \\
\text { (straight } \\
\text { blister } \\
\text { model) } \\
\mathrm{G}_{\mathrm{c}}[\mathrm{N} / \mathrm{m}]\end{array}$} & \multirow{3}{*}{$\begin{array}{l}\text { Buckling- } \\
\text { driven } \\
\text { (pinned- } \\
\text { circular } \\
\text { blister } \\
\text { model) } \\
\mathrm{G}_{\mathrm{c}}[\mathrm{N} / \mathrm{m}]\end{array}$} \\
\hline & & & & & & & & & & & \\
\hline & & & & & & & & $\Omega$ & $\begin{array}{l}\mathrm{G}_{\mathrm{c}} \\
{[\mathrm{N} / \mathrm{m}]}\end{array}$ & & \\
\hline [24] & 0.300 & 150.0 & 0.30 & 14.40 & 1.414 & - & - & 1.500 & 1.213 & 2.275 & 1.661 \\
\hline [31] & 0.300 & 171.8 & 0.288 & 22.93 & 1.000 & - & - & 1.734 & 0.462 & 0.943 & 0.747 \\
\hline [19] & 0.130 & 186.0 & 0.33 & 16.00 & 0.500 & - & - & 1.894 & 0.041 & 0.090 & 0.072 \\
\hline [12] & 0.225 & 175.0 & 0.30 & 20.00 & 1.000 & - & - & 2.055 & 0.285 & 0.667 & 0.548 \\
\hline [25] & 0.120 & 329.0 & 0.30 & 9.84 & 2.700 & 0.328 & 53.046 & 2.375 & $\begin{array}{l}0.509 \\
0.524 \\
0.525\end{array}$ & $\begin{array}{l}1.353 \\
8.235 \\
9.630\end{array}$ & $\begin{array}{l}1.135 \\
16.432 \\
23.514\end{array}$ \\
\hline
\end{tabular}

\section{Conclusions}

The PEC-driven approach provides ' $\Omega$ formulae' which: (1) give accurate predictions of the formation condition and the two local morphology parameters, namely, the half-width $R$ and height $A_{x}$ for TCBs of any shape; (2) give accurate predictions of the two global morphology parameters, namely, the wavelength $\lambda$ and transverse amplitude $A_{y}$ for TCBs of sinusoidal shape provided that the transverse amplitude-to-wavelength ratio $A_{y} / \lambda$ is less than approximately $1 / 10$; (3) give accurate predictions of the residual stress $\sigma_{0}$ and interface fracture toughness $G_{\mathrm{c}}$ by using the measured morphology parameters.

Concerning the conventional buckling-driven approaches: The buckling-driven straight blister model severely overestimates the residual stress $\sigma_{0}$ while the buckling-driven pinnedcircular blister model also significantly overestimates the residual stress $\sigma_{0}$ when $\Omega$ is not close to $3 / 2$. Both buckling-driven models severely overestimate the interface fracture toughness $G_{\mathrm{c}}$.

The PEC-driven approach and its $\Omega$ formulae provide a valuable means to better design film/substrate material systems. A significant milestone has been reached in understanding the mechanics and reliability of thin films. 


\section{Data availability}

The authors confirm that the data supporting the findings of this study are available within the article.

\section{References}

[1] L.B. Freund, S. Suresh, Thin Film Materials: Stress, Defect Formation and Surface Evolution, Cambridge University Press, 2004.

[2] S.-J. Yu, S.-C. Li, Y. Ni, H. Zhou, Size dependent morphologies of brittle silicon nitride thin films with combined buckling and cracking, Acta Mater. 127 (2017) 220229. doi:10.1016/j.actamat.2017.01.038.

[3] S. Cai, D. Breid, A.J. Crosby, Z. Suo, J.W. Hutchinson, Periodic patterns and energy states of buckled films on compliant substrates, J. Mech. Phys. Solids. 59 (2011) 1094-1114. doi:10.1016/j.jmps.2011.02.001.

[4] G. Gioia, M. Ortiz, Delamination of Compressed Thin Films, in: Adv. Appl. Mech., Elsevier, 1997: pp. 119-192. doi:10.1016/S0065-2156(08)70386-7.

[5] B. Audoly, Stability of Straight Delamination Blisters, Phys. Rev. Lett. 83 (1999) 4124-4127. doi:10.1103/PhysRevLett.83.4124.

[6] H. Chai, Three-dimensional fracture analysis of thin-film debonding, Int. J. Fract. 46 (1990) 237-256. doi:10.1007/BF00037155.

[7] J.W. Hutchinson, M.D. Thouless, E.G. Liniger, Growth and configurational stability of circular, buckling-driven film delaminations, Acta Metall. Mater. 40 (1992) 295-308. doi:10.1016/0956-7151(92)90304-W.

[8] H.M. Jensen, I. Sheinman, Straight-sided, buckling-driven delamination of thin films at high stress levels, Int. J. Fract. 110 (2001) 371-385. doi:10.1023/A:1010821918325.

[9] M.W. Moon, H.M. Jensen, J.W. Hutchinson, K.H. Oh, A.G. Evans, The characterization of telephone cord buckling of compressed thin films on substrates, J. Mech. Phys. Solids. 50 (2002) 2355-2377. doi:10.1016/S0022-5096(02)00034-0.

[10] H.M. Jensen, I. Sheinman, Numerical analysis of buckling-driven delamination, Int. J. Solids Struct. 39 (2002) 3373-3386. doi:10.1016/S0020-7683(02)00158-0.

[11] J.-Y. Faou, S. Grachev, E. Barthel, G. Parry, From telephone cords to branched buckles: A phase diagram, Acta Mater. 125 (2017) 524-531. doi:10.1016/j.actamat.2016.12.025.

[12] Y. Ni, S. Yu, H. Jiang, L. He, The shape of telephone cord blisters, Nat. Commun. 8 
(2017) 14138. doi:10.1038/ncomms14138.

[13] J.W. Hutchinson, M.Y. He, A.G. Evans, The influence of imperfections on the nucleation and propagation of buckling driven delaminations, J. Mech. Phys. Solids. 48 (2000) 709-734. doi:10.1016/S0022-5096(99)00050-2.

[14] M.Y. He, A.G. Evans, J.W. Hutchinson, Effects of morphology on the decohesion of compressed thin films, Mater. Sci. Eng. A. 245 (1998) 168-181. doi:10.1016/S09215093(97)00848-4.

[15] V.K. Tolpygo, D.R. Clarke, Spalling failure of $\alpha$-alumina films grown by oxidation: I. Dependence on cooling rate and metal thickness, Mater. Sci. Eng. A. 278 (2000) 142150. doi:10.1016/S0921-5093(99)00581-X.

[16] V.K. Tolpygo, D.R. Clarke, Spalling failure of $\alpha$-alumina films grown by oxidation. II. Decohesion nucleation and growth, Mater. Sci. Eng. A. 278 (2000) 151-161. doi:10.1016/S0921-5093(99)00582-1.

[17] S. Wang, C.M. Harvey, B. Wang, Room temperature spallation of $\alpha$-alumina films grown by oxidation, Eng. Fract. Mech. 178 (2017) 401-415. doi:10.1016/j.engfracmech.2017.03.002.

[18] C.M. Harvey, B. Wang, S. Wang, Spallation of thin films driven by pockets of energy concentration, Theor. Appl. Fract. Mech. 92 (2017) 1-12. doi:10.1016/j.tafmec.2017.04.011.

[19] M. He, C. Gaire, G.-C. Wang, T.-M. Lu, Study of metal adhesion on porous low-k dielectric using telephone cord buckling, Microelectron. Reliab. 51 (2011) 847-850. doi:10.1016/j.microrel.2010.11.015.

[20] K. Xiao, Z.S. Guan, G.J. Wang, L. Jiang, D. Ben Zhu, Y.R. Wang, Laser-induced wavy pattern formation in metal thin films, Appl. Phys. Lett. 85 (2004) 1934-1936. doi:10.1063/1.1787891.

[21] Z.-J. Liu, N. Jiang, Y.G. Shen, X. Li, Stress-induced surface damages in Ti-Si-N films grown by magnetron sputtering, Thin Solid Films. 516 (2008) 7609-7614. doi:10.1016/j.tsf.2008.04.090.

[22] Y.-D. Sun, Q.-X. Chen, Y.-F. Feng, J. Chen, S.-J. Yu, Buckling morphologies and interfacial properties of silicon nitride films deposited on float glass substrates, Surf. Rev. Lett. 22 (2015) 1550046. doi:10.1142/S0218625X15500468.

[23] S.-J. Yu, X.-F. Xiao, M.-G. Chen, H. Zhou, J. Chen, P.-Z. Si, Z.-W. Jiao, Morphological selections and dynamical evolutions of buckling patterns in SiAlNx films: From straight-sided to telephone cord or bubble structures, Acta Mater. 64 
(2014) 41-53. doi:10.1016/j.actamat.2013.11.038.

[24] A.A. Abdallah, P.C.P. Bouten, J.M.J. den Toonder, G. de With, The effect of moisture on buckle delamination of thin inorganic layers on a polymer substrate, Thin Solid Films. 516 (2008) 1063-1073. doi:10.1016/j.tsf.2007.06.157.

[25] J.-Y. Faou, G. Parry, S. Grachev, E. Barthel, How Does Adhesion Induce the Formation of Telephone Cord Buckles?, Phys. Rev. Lett. 108 (2012) 116102. doi:10.1103/PhysRevLett.108.116102.

[26] N.R. Moody, D.P. Adams, M.J. Cordill, D.F. Bahr, A.A. Volinsky, Plasticity effects on interfacial fracture of thin gold films, in: Thin Film., 9th International Conference on the Mechanical Behavior of Materials, 2003.

[27] A.A. Volinsky, J.B. Vella, W.W. Gerberich, Fracture toughness, adhesion and mechanical properties of low-K dielectric thin films measured by nanoindentation, Thin Solid Films. 429 (2003) 201-210. doi:10.1016/S0040-6090(03)00406-1.

[28] M.D. Thouless, Combined Buckling and Cracking of Films, J. Am. Ceram. Soc. 76 (1993) 2936-2938. doi:10.1111/j.1151-2916.1993.tb04044.x.

[29] H.Y. Yu, C. Kim, S.C. Sanday, Buckle formation in vacuum-deposited thin films, Thin Solid Films. 196 (1991) 229-233. doi:10.1016/0040-6090(91)90366-6.

[30] M.J. Cordill, D.F. Bahr, N.R. Moody, W.W. Gerberich, Adhesion measurements using telephone cord buckles, Mater. Sci. Eng. A. 443 (2007) 150-155. doi:10.1016/j.msea.2006.08.027.

[31] A. Kleinbichler, J. Zechner, M.J. Cordill, Buckle induced delamination techniques to measure the adhesion of metal dielectric interfaces, Microelectron. Eng. 167 (2017) 63-68. doi:10.1016/j.mee.2016.10.020.

[32] P. Waters, A.A. Volinsky, Stress and Moisture Effects on Thin Film Buckling Delamination, Exp. Mech. 47 (2007) 163-170. doi:10.1007/s11340-006-9346-4.

[33] S.-J. Yu, M.-G. Chen, J. Chen, H. Zhou, Y.-J. Zhang, P.-Z. Si, Spatial and kinetic evolutions of telephone cord buckles, Surf. Coatings Technol. 228 (2013) 258-265. doi:10.1016/j.surfcoat.2013.04.038.

[34] S.-J. Yu, M.-G. Chen, P.-Z. Si, H. Zhou, J. Chen, X.-F. Zhang, Y.-J. Zhang, Transitions from straight-sided to telephone cord buckles in SiAlNx films, Thin Solid Films. 550 (2014) 480-485. doi:10.1016/j.tsf.2013.10.145.

[35] S. Wang, C.M. Harvey, B. Wang, A. Watson, Post-local buckling-driven delamination in bilayer composite beams, Compos. Struct. 133 (2015) 1058-1066. doi:10.1016/j.compstruct.2015.08.012. 
[36] C.M. Harvey, M.R. Eplett, S. Wang, Experimental assessment of mixed-mode partition theories for generally laminated composite beams, Compos. Struct. 124 (2015) 10-18. doi:10.1016/j.compstruct.2014.12.064.

[37] C.M. Harvey, S. Wang, Experimental assessment of mixed-mode partition theories, Compos. Struct. 94 (2012) 2057-2067. doi:10.1016/j.compstruct.2012.02.007.

[38] S. Wang, C. Harvey, A theory of one-dimensional fracture, Compos. Struct. 94 (2012) 758-767. doi:10.1016/j.compstruct.2011.09.011.

[39] S. Wang, C.M. Harvey, Mixed mode partition theories for one dimensional fracture, Eng. Fract. Mech. 79 (2012) 329-352. doi:10.1016/j.engfracmech.2011.11.013.

[40] J.W. Hutchinson, Z. Suo, Mixed Mode Cracking in Layered Materials, in: Adv. Appl. Mech., 1991: pp. 63-191.

[41] C.M. Harvey, J.D. Wood, S. Wang, A. Watson, A novel method for the partition of mixed-mode fractures in 2D elastic laminated unidirectional composite beams, Compos. Struct. 116 (2014) 589-594. doi:10.1016/j.compstruct.2014.05.041.

\section{Appendix A: Introduction to the buckling-driven approach}

TCBs have been studied extensively using buckling-driven straight [40] and pinnedcircular [9] models. Some essential formulae are recorded here.

In the buckling-driven straight blister model [40], the height $A_{x}$ is given by

$$
\frac{A_{x}}{h}=\left[\frac{4}{3}\left(\frac{\sigma_{0}}{\sigma_{\mathrm{c}}}-1\right)\right]^{1 / 2},
$$

where $\sigma_{\mathrm{c}}$ is the critical buckling stress, which is given by

$$
\sigma_{\mathrm{c}}=\frac{\pi^{2} E}{12\left(1-v^{2}\right)}\left(\frac{h}{R}\right)^{2} .
$$

The energy release rate at the crack tip is

$$
G(\psi)=\frac{h\left(1-v^{2}\right) \sigma_{0}^{2}}{2 E}\left(1-\frac{\sigma_{\mathrm{c}}}{\sigma_{0}}\right)\left(1+3 \frac{\sigma_{\mathrm{c}}}{\sigma_{0}}\right) .
$$

The phase angle $\psi=\arctan \left(G_{\mathrm{II}} / G_{\mathrm{I}}\right)^{1 / 2}$ can be calculated from

$$
\tan \psi=\frac{4 \cos \omega+\sqrt{3}\left(A_{x} / h\right) \sin \omega}{-4 \sin \omega+\sqrt{3}\left(A_{x} / h\right) \cos \omega},
$$


in which the parameter $\omega$ is a function of the Dundurs parameters, which describe the elastic mismatch between the film and the substrate respectively.

In the buckling-driven pinned-circular blister model [9], the height $A_{x}$ is given by

$$
\frac{A_{x}}{h}=\left[\frac{1}{0.2473(1+v)+0.2231\left(1-v^{2}\right)}\left(\frac{\sigma_{0}}{\sigma_{\mathrm{c}}}-1\right)\right]^{1 / 2},
$$

where $\sigma_{\mathrm{c}}$ is the critical buckling stress, which is given by

$$
\sigma_{\mathrm{c}}=\frac{42.67 E}{12\left(1-v^{2}\right)}\left(\frac{h}{2 R}\right)^{2}
$$

The energy release rate at the crack tip is

$$
G(\psi)=\frac{h(1-v) \sigma_{0}^{2}}{E[1+0.9021(1-v)]}\left[1-\left(\frac{\sigma_{\mathrm{c}}}{\sigma_{0}}\right)^{2}\right] .
$$

The phase angle is

$$
\tan \psi=\frac{\cos \omega+0.2486(1+v)\left(A_{x} / h\right) \sin \omega}{-\sin \omega+0.2486(1+v)\left(A_{x} / h\right) \cos \omega} .
$$

Two fracture propagation criteria, proposed in Ref. [40], are often used to determine the interface fracture toughness between the film and the substrate. One is the linear propagation criterion:

$$
G_{\mathrm{c}}=G_{\mathrm{Ic}}\left[1+(\Lambda-1) \sin ^{2} \psi\right]^{-1}
$$

The other is the nonlinear propagation criterion:

$$
G_{\mathrm{c}}=G_{\mathrm{Ic}}\left[1+(1-\Lambda) \tan ^{2} \psi\right]^{-1} .
$$

Note that the parameter $\Lambda$ varies from 0 to 1 .

A brief explanation of the buckling-driven approach in the study of TCBs is illustrated in Fig. A.1. The variations of both the normalized energy release rate $G / u_{0}$ and the normalized interface fracture toughness $G_{\mathrm{c}} / u_{0}$ are shown with respect to the normalized blister growth $R / R_{\mathrm{c}}$. The compressive residual strain energy density is $u_{0}=(1-v) \sigma_{0}^{2} h / E$. There are two stages of blister growth in the buckling-driven approach. During the first stage, the separation nucleates and grows without bending-away from the substrate resulting in zero energy release rate $G$ at the separation edge. When the size of separation reaches the conventional buckling 
size, that is, $R=R_{\mathrm{c}}$, the separated film starts to bend away from the substrate, resulting in energy release rate at the separation edge, that is, a blister is formed. At a critical size slightly larger than the conventional buckling size, that is, $R=R_{1}$ in Fig. A.1, the energy release rate $G$ exceeds the interface fracture toughness $G_{\mathrm{c}}$ and the second stage starts. The blister quickly grows to a certain size, that is, $R=R_{2}$, beyond which the energy release rate is lower than the interface fracture toughness, and then stops.

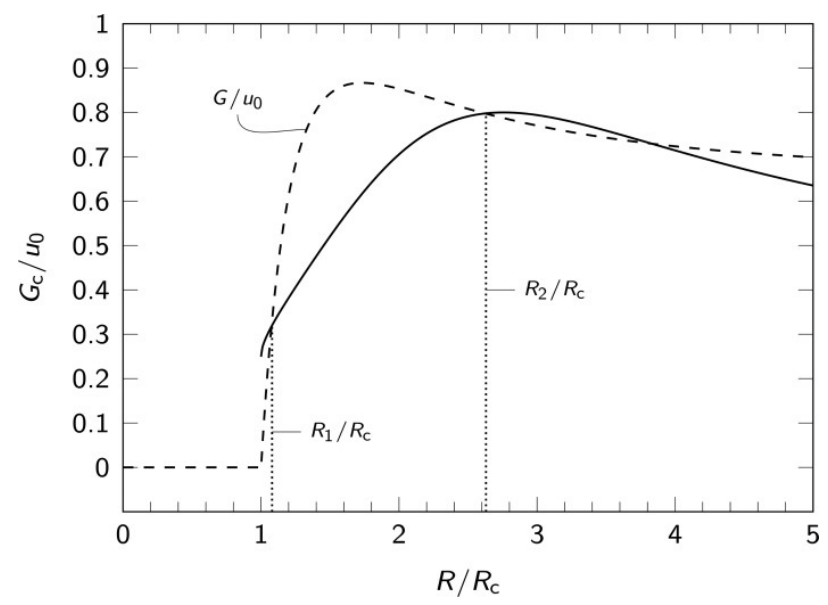

Fig. A.1. Illustration of buckling-driven approach. 


\section{Appendix B: Independent experimental measurements of telephone cord blister morphology}

Table B.1. Material properties and measurements of residual stress and TCB morphologies.

\begin{tabular}{|c|c|c|c|c|c|c|c|c|c|}
\hline \multirow[b]{2}{*}{ Ref. } & \multicolumn{4}{|l|}{ Films } & \multicolumn{5}{|c|}{ Measurements } \\
\hline & Material & $\mathrm{E}$ [GPa] & $v$ & $\begin{array}{l}\mathrm{h} \\
{[\mu \mathrm{m}]}\end{array}$ & $\overline{\sigma_{0}[\mathrm{GPa}]}$ & $\mathrm{A}_{\mathrm{x}}[\mu \mathrm{m}]$ & $2 \mathrm{R}[\mu \mathrm{m}]$ & $\lambda[\mu \mathrm{m}]$ & $\mathrm{A}_{\mathrm{y}}[\mu \mathrm{m}]$ \\
\hline [28] & $\mathrm{Si}$ & 105 & 0.19 & 18.00 & - & 58.80 & 188.22 & - & - \\
\hline \multirow{2}{*}{ [29] } & $\mathrm{Fe}$ & 200 & 0.2 & 0.92 & - & - & 60.56 & 99.16 & 9.86 \\
\hline & $\mathrm{Fe}$ & 200 & 0.2 & 0.59 & - & - & 48.00 & 85.00 & - \\
\hline \multirow{4}{*}{ [30] } & Tungsten & 411 & 0.28 & 0.10 & - & 0.817 & 15.51 & - & - \\
\hline & Tungsten & 411 & 0.28 & 0.20 & - & 0.652 & 10.56 & - & - \\
\hline & Tungsten & 411 & 0.28 & 0.225 & - & 1.40 & 34.70 & - & - \\
\hline & Tungsten & 411 & 0.28 & 0.30 & - & 1.60 & 38.80 & 40.09 & 3.98 \\
\hline [31] & TiW & 171.8 & 0.288 & 0.30 & 1.000 & 1.25 & 22.93 & - & - \\
\hline \multirow{3}{*}{ [27] } & TiW & 275 & 0.3 & 1.00 & - & - & 78.09 & 82.77 & 8.17 \\
\hline & TiW & 275 & 0.3 & 1.00 & - & - & 52.96 & 56.79 & 5.47 \\
\hline & TiW & 275 & 0.3 & 1.00 & - & - & 78.09 & 118.20 & 11.36 \\
\hline [32] & TiW & 275 & 0.3 & 1.00 & - & - & 94.00 & 108.13 & 10.82 \\
\hline \multirow{4}{*}{ [33] } & $\operatorname{SiAlN}_{x}$ & 200 & 0.3 & 0.38 & - & - & 39.28 & 44.94 & 4.41 \\
\hline & $\operatorname{SiAlN}_{x}$ & 200 & 0.3 & 0.38 & - & 1.50 & 32.00 & 40.00 & - \\
\hline & $\operatorname{SiAlN}_{x}$ & 200 & 0.3 & 0.38 & - & - & 33.86 & 46.36 & 5.15 \\
\hline & $\operatorname{SiAlN}_{\mathrm{x}}$ & 200 & 0.3 & 0.38 & - & 1.50 & 31.40 & 40.33 & - \\
\hline [34] & $\operatorname{SiAlN}_{\mathrm{x}}$ & 200 & 0.3 & 0.44 & - & - & 34.90 & 42.20 & 4.16 \\
\hline \multirow{5}{*}{ [22] } & $\operatorname{SiAlN}_{x}$ & 200 & 0.3 & 0.44 & - & 1.58 & 39.44 & 57.31 & 4.62 \\
\hline & $\operatorname{SiAlN}_{\mathrm{x}}$ & 200 & 0.3 & 0.38 & - & - & 46.38 & 61.45 & 6.96 \\
\hline & $\operatorname{SiAlN}_{\mathrm{x}}$ & 200 & 0.3 & 0.62 & - & - & 53.33 & 57.97 & 5.80 \\
\hline & $\operatorname{SiAlN}_{x}$ & 200 & 0.3 & 0.86 & - & - & 73.04 & 82.32 & 8.12 \\
\hline & $\operatorname{SiAlN}_{x}$ & 200 & 0.3 & 1.10 & - & 4.20 & 92.00 & 106.67 & 13.13 \\
\hline \multirow{3}{*}{ [23] } & $\operatorname{SiAlN}_{\mathrm{x}}$ & 200 & 0.3 & 1.10 & - & - & 48.00 & 60.90 & 3.20 \\
\hline & $\operatorname{SiAlN}_{\mathrm{x}}$ & 200 & 0.3 & 1.10 & - & - & 63.67 & 80.54 & 5.39 \\
\hline & $\operatorname{SiAlN}_{x}$ & 200 & 0.3 & 1.10 & - & - & 71.53 & 95.64 & 9.39 \\
\hline [24] & $\mathrm{SiN}_{\mathrm{x}}$ & 150 & 0.3 & 0.30 & 1.414 & 0.84 & 14.40 & - & - \\
\hline [25] & Molybdenum & 329 & 0.3 & 0.12 & 2.700 & - & 9.84 & 32.70 & 10.05 \\
\hline \multirow{3}{*}{ [12] } & $\operatorname{SiAlN}_{x}$ & 200 & 0.3 & 0.40 & - & - & 59.29 & 73.57 & 5.99 \\
\hline & $\operatorname{SiAlN}_{\mathrm{x}}$ & 200 & 0.3 & 0.40 & - & - & 127.43 & 108.78 & 11.59 \\
\hline & $\mathrm{Ta}$ & 175 & 0.3 & 0.225 & 1.00 & 1.10 & 20.53 & 20.53 & 1.64 \\
\hline [9] & $\begin{array}{l}\text { Diamond- } \\
\text { like carbon }\end{array}$ & 120 & 0.3 & 0.13 & - & 0.527 & 3.70 & 5.01 & 0.47 \\
\hline [19] & $\mathrm{Ta}$ & 186 & 0.33 & 0.13 & 0.500 & 0.60 & 16.00 & - & - \\
\hline \multirow{3}{*}{ [26] } & Gold & 79 & 0.4 & 0.01 & - & - & 24.16 & 20.23 & 2.09 \\
\hline & Gold & 79 & 0.4 & 0.01 & - & - & 24.42 & 20.97 & 2.13 \\
\hline & Gold & 79 & 0.4 & 0.20 & - & - & 27.29 & 31.95 & 3.26 \\
\hline
\end{tabular}

